\title{
Programa educativo en prevención del feminicidio íntimo y violencia en parejas de la ciudad de El Alto
}

\section{Educational program on prevention of intimate feminicide and violence in couples in the city of El Alto}

\author{
Denny Judith Quispe Sangalli \\ sidneysjudith1408@gmail.com \\ Código ORCID: 0000-0001-7046-5733 \\ Fundación Sariry, Viacha, Bolivia
}

\section{RESUMEN}

- Artículo recibido en octubre 2020

- Arbitrado en noviembre 2020

- Aceptado en diciembre 2020

- Publicado en enero 2021

\begin{abstract}
Investigación cuyo objetivo fue determinar las causas más relevantes para el incremento de los casos de feminicidio íntimo en la ciudad de El Alto, Bolivia. El estudio se abordó desde un enfoque cualitativo, de tipo descriptivo, bajo el diseño de investigación no experimental. Los resultados de la investigación arrojaron que los factores sociales, culturales, económicos y educativos influyen para que la pareja esté en situación de violencia, debido al "aprendizaje violento" dado desde la historia familiar de ambos, como también al aprendizaje que se produce en el ciclo violento por la incapacidad de resolución de conflictos, partiendo que los agresores minimizan los hechos. Se creó un programa educativo de prevención de "feminicidio íntimo", violencia en parejas denominado "Formemos juntos y juntas una familia sin violencia" para coadyuvar en la necesaria sensibilización acerca de la problemática.
\end{abstract}

Palabras clave: Feminicidio íntimo; violencia; familia; educación; prevención

\begin{abstract}
Research whose objective was to determine the most relevant causes for the increase in cases of intimate feminicide in the city of El Alto, Bolivia. The study was approached from a qualitative, descriptive approach, under the non-experimental research design. The results of the research showed that social, cultural, economic and educational factors influence the couple being in a situation of violence, due to the "violent learning" given from the family history of both, as well as the learning that occurs in the violent cycle due to the inability to resolve conflicts, assuming that the aggressors minimize the facts. An educational program for the prevention of "intimate feminicide", violence in couples called "Let's form a family without violence together" was created to help raise awareness about the problem.
\end{abstract}

Keywords: Intimate feminicide; violence; family; education; prevention 


\section{INTRODUCCIÓN}

La presente investigación se refiere al tema del "feminicidio íntimo" y el ciclo de la violencia que se puede definir como la violencia extrema y muerte hacia las mujeres, por el solo hecho de pertenecer a este género, en el cual los principales agresores $\mathrm{O}$ victimarios son las propias parejas o con las que ellas mantenían una relación afectiva. La característica principal de este fenómeno se vislumbra ante los antecedentes a los hechos de feminicidio, pues en estos casos se ha precedido al mismo un ciclo de violencia en las parejas; como también la concepción de que el hombre es propietario de la vida de la mujer.

Para analizar esta problemática es necesario mencionar sus causas. Una de ellas es el factor educativo, pues se presenta el ciclo violento y la incapacidad de la resolución de conflictos, estos factores y otros han provocado que las parejas aprendan a (o se convenzan de) resolver los conflictos mediante la violencia. En esto también intervienen factores sociales, culturales y económicos entre la pareja con antecedentes de una historia familiar violenta, sea de uno de ellos o de ambos.

En el marco de lo antes planteado, es destacable expresar que la investigación se realizó por el interés de conocer los factores externos que implícitamente pueden intervenir en una relación de pareja en situación de violencia; asimismo se refleja que Bolivia está aún sumergida en una sociedad patriarcal en la que se otorga al hombre el título de proveedor de la familia, así como de autoridad que hace a un lado el papel de la mujer, desvalorizando, por ende, sus logros.

Por otro lado está establecer el papel de la educación en esta problemática, puesto que los casos de feminicidio, en lugar de reducirse, van en aumento, siendo que los registros de las muertes son las más altas a nivel latinoamericano; en el caso de Bolivia, se encuentra entre los primeros 25 países que ejercen violencia hacia las mujeres.

En el ámbito profesional, desde la rama científica social que son las ciencias de la educación, el interés surgió en realizar un programa educativo en prevención del "feminicidio íntimo" y violencia en parejas, como medida para reducir casos violentos y así fomentar la empatía, la comunicación asertiva y la resolución de conflictos; todo esto con el objetivo de que la familia ya no esté en situación de violencia.

Debido a lo anteriormente expuesto, el presente estudio adquirió relevancia social y epistemológica porque toma en cuenta factores sucedidos de hechos en particular, y no obstante pretende, al mismo tiempo, sacar a la luz los 
factores principales para la presencia de este hecho en particular. Por ello, se ha valorado su preeminencia tanto en su desarrollo como en su presentación a la sociedad, por sus siguientes elementos:

- Justificación social: La presente investigación posee, en su sentido de trabajo de campo, distintos elementos de exploración social, tratando de vislumbrar sus características más relevantes. Es un estudio que posee un carácter social en cuanto a los datos adquiridos y el tratamiento de los mismos para una sistematización que pueda ser leída no solo por especialistas de esta temática, sino por el público en general.

- Justificación educativa: Se estima que el trabajo expuesto conformó un aporte primordial a investigaciones que exploran los problemas de género en Bolivia y el resto del mundo. También se destaca que fue un estudio precursor a las diversas temáticas alrededor de situaciones de género, sirviendo también, como punto de partida o refuerzo a investigaciones futuras.

\section{- Justificación}

epistemológica $\quad \mathbf{y}$ documental: La naturaleza epistemológica del estudio se apoya en la inclusión de elementos extraídos de la realidad, pero también se fundamenta como un documento respaldado bibliográficamente, tanto en su marco teórico, como en sus dimensiones prácticas. Es pertinente así expresar que se tomaron en cuenta los factores históricos, sociales, culturales, económicos y educativos que brindaron las fuentes primarias y secundarias durante la investigación.

Como pregunta eje del estudio se consideró la siguiente: ¿Qué características debiera tener una propuesta educativa para la prevención de violencia y "feminicidio íntimo" en parejas del distrito uno de la ciudad de El Alto?

De allí que el objetivo de investigación fue proponer un programa educativo para la prevención de violencia y "feminicidio íntimo" a parejas del distrito 1 de la ciudad de El Alto.

En las próximas líneas se hace referencia a las nociones principales que sustentaron y contextualizaron el propósito del estudio.

\section{El feminicidio}

El feminicidio es la fase final de la violencia hacia las mujeres donde no se toma en cuenta los derechos humanos y se los violenta en todas las formas, en todos los espacios públicos, privados y entre los estratos sociales.

Así, Lagarde (2006) lo define de la siguiente manera:

El feminicidio es una ínfima parte visible de la violencia contra niñas y mujeres; sucede como culminación caracterizada por la 
violación reiterada y sistemática de los derechos humanos de las mujeres. Su común denominador es el género: niñas y mujeres son violentadas con crueldad por el solo hecho de ser mujeres, y en algunos casos son asesinadas como culminación de dicha violencia pública o privada. (p. 21)

No es extraño hablar sobre el tema, ya que los medios de información y de comunicación, muestran que en estos casos los agresores o asesinos son los mismos esposos o novios que han tenido una relación afectiva con la víctima.

Lagarde (2012) aporta en otro texto:

El feminicidio se fragua en la desigualdad estructural entre mujeres y hombres, así como en la dominación de los hombres sobre las mujeres, que tienen en la violencia de género, un mecanismo de reproducción de la opresión de las mujeres. De esas condiciones estructurales surgen otras condiciones culturales como son el ambiente ideológico y social de machismo y misoginia, y de normalización de la violencia contra las mujeres. (p. 217)

En Latinoamérica esta noción ha sido reinterpretado en dos términos: femicidio y feminicidio, los cuales intervienen desde dos elementos que inducen a estos hechos de violencia hacia las mujeres que son la "misoginia" y la responsabilidad política social y estatal al favorecer o impedir que se esclarezcan estos hechos; que si bien existen leyes y políticas de Estado para la prevención, seguimiento y protección de los casos que son denunciados, no están siendo seriamente tomados en cuenta por el sistema legal.

Este tipo de violencia, por parte de las autoridades, se considera como violencia institucional, puesto que es negligente, discriminatoria e irresponsable ante la búsqueda de justicia y respeto de los derechos humanos hacia las mujeres.

\section{Principales causas acerca de violencia hacia las mujeres}

Las principales causas para que se ejerza violencia hacia las mujeres pueden tener raíces históricas, culturales, sociales, económicas y educativas. En esta ocasión, para efectos del presente artículo, se abordará el referido a lo educativo.

\section{Factor educativo}

En este aspecto se tomarán tres puntos: la importancia de la educación, la educación patriarcal y su currículo oculto $\mathrm{y}$, por último, la educación basada en la equidad de género. 


\section{La importancia de la educación}

La educación es un pilar trascendental para la sociedad como también parte significativa de desarrollo, siendo una responsabilidad del Estado y un derecho para todos los ciudadanos: "En la actualidad se concibe a la educación como el medio de transmisión de conocimientos y actitudes por el que el niño se inserta en la sociedad y en la cultura" (Grupo Cultural, 2010, p. 100).

La educación es concebida como una ciencia integral e interdisciplinaria, que dispone de varias ramas científicas, entre las que se encuentran: socio antropología, psicología, biología, política, etc. Donde la persona vive en un determinado momento histórico, contexto social y cultural. Como se explica desde el punto de vista socioantropológico a continuación. "La socio-antropología tiene como objeto de observación privilegiado la relación individuo- sociedad. Para orientar la educación, el proyecto - persona se enriquece con los aspectos "ético sociales" y "cognitivos" de la vida personal indispensables para vivir en contextos comunitarios." (Frabonni, 2002, p. 132). Donde el objetivo de la educación es, en líneas generales, formar a mujeres y hombres con ética para relacionarse con las demás personas, con la capacidad de resolver, reflexionar y actuar solucionando conflictos desde su realidad.
Desde el punto de vista psicológico se menciona lo siguiente:

Las dimensiones de la esfera individual son el objeto de estudio privilegiado por la psicología. La contribución de este acercamiento cognitivo a la educación es el estímulo al enriquecimiento de la dimensión emotivo-afectiva y estética de la vida personal, promoviendo un desarrollo equilibrado y armónico del hombre $y$ de la mujer contemporánea. (Frabonni, 2002, p. 133)

Donde la educación tiene el papel de enriquecer a hombres y mujeres en la empatía que debe existir entre ambos géneros, en la sensibilidad de resolver conflictos e interrelacionarse acerca de las situaciones que se viven día a día y promover el desarrollo, fomentando la igualdad, equidad de derechos y responsabilidades de hombres y mujeres.

\section{La educación patriarcal}

La educación patriarcal no es más que el reflejo de la colonización que ha influido a lo largo de la historia en varios países incluso el nuestro, ha incidido en la historia, sociedad, cultura, economía y en la educación.

Las políticas educativas a lo largo del tiempo han obedecido a un poder patriarcal. "Así pues, la escuela, mediante los contenidos, convierte al 
cuerpo en objeto de poder, bueno como dominante o dominado. La cuestión en la escuela es disciplinar el cuerpo" (Patzi, 2007, p.33)

Se disciplina el cuerpo de la mujer desde la familia, se le va moldeando en la escuela de forma sumisa, se la forma para trabajos del hogar, se les da poca participación en clases, no se la orienta en educación sexual y reproductiva.

Desde la familia, los sistemas educativos y la sociedad se enseña al hombre a ser violento ante lo que les molesta, no conoce otra manera de solucionar un conflicto. Por su parte, a la mujer a soportar la violencia donde el machismo en mujeres y hombres como también el sexismo son la forma de expresión ante una sociedad misógina, la cual es difícil de construir esas concepciones.

\section{El currículum oculto del patriarcado}

El currículum oculto muestra mensajes indirectos que se dan en las instituciones educativas $y$ en otros espacios que son inconscientemente mostradas a los sujetos de educación, estas son aprendidas desde la observación, hasta los comportamientos que se muestran por los maestros o maestras que tienen encarnizado la violencia, sobre todo hacia las mujeres; esto también se refleja en diferentes espacios, sean en la familia, escuela, calle, entre otros.
Las formas particulares de atención y trato que reciben los niños y las niñas en las escuelas, así como la relación que establecen con sus maestras y maestros. En el aula los niños demandan mayor atención por parte de la maestra, reclaman ser escuchados y expresan abiertamente su enojo cuando ven afectados sus intereses y posibilidades de participación, son más inquietos, corren $\mathrm{y}$ gritan con mayor soltura que las niñas. En el caso de las niñas se les exige con mayor severidad que sean "bien portadas", reciben más observaciones y reprobación por parte del docente ante conductas eruptivas, por lo que son calladas, aprenden a esperar y guardar silencio (Valenzuela, 2001, s.n.)

E1 patriarcado como sistema de poder se ha reflejado directa $o$ indirectamente, esto obedeciendo a un sistema político, social y económico, donde el sistema curricular ha sido influenciado por estos propósitos. Como se menciona a continuación:

En un sistema escolar, es difícil que la colectividad elabore contenidos curriculares de acuerdo a sus intereses y su situación. Esa elaboración siempre la realizan agentes de la cultura legítima que primero velan los intereses generales, traducidos en el interés 
nacional, requisito éste esencial para la reproducción de la clase dominante. (Patzi, 2007, p. 32)

Este autor menciona que todo sistema escolar $u$ otro espacio donde se educa obedecen a un sistema político como es la del patriarcado; se legitima los derechos y comportamientos del hombre, en cambio al de las mujeres recae las responsabilidades y se les enseña comportamientos sexistas.

Se reproducen y fortalece la transmisión de los estereotipos de género, lo tradicionalmente masculino y lo tradicionalmente femenino, asignándoles de forma desigual distintas funciones, actitudes, características y motivaciones (...) también, se manifiesta en las expectativas diferenciadas de rendimiento y comportamiento de las alumnas y los alumnos, el uso del lenguaje diferenciado para dirigirse a unos $y$ otras $e$ imágenes sesgadas en los libros de texto y los materiales educativos. (CIDEM, 2010, p. 9)

La escuela, como medio de reproducción del sistema patriarcal, hace su influencia en los comportamientos de género construyéndose mitos; no es más que una construcción social que ha hecho que la violencia hacia la mujer sea de la más sutil hasta la más directa en muchos centros educativos primarios, secundarios e inclusive centros de educación superior.
Las conductas de violencia e intolerancia si bien son sancionados, en los niños son más aceptadas y menos castigadas porque se considera que son parte de su "naturaleza", en cambio en las niñas se les recrimina al no comportarse de una manera más sutil y dócil, según el esquema preestablecido de lo que se considera la feminidad. (Valenzuela, 2001, s.n.)

El machismo se ve reflejado no solo en el hombre sino también entre mujeres; como menciona CIDEM (2010). "Este currículo no se limita sólo al ámbito educativo, sino que recoge las normas sociales con las que las personas se relacionan, hay una relación directa entre la escuela y sociedad" (p. 9).

Actualmente el currículo oculto del patriarcado se ha evidenciado. Los profesionales en educación reconocen que se da una educación sexista y es hoy en día una de las grandes preocupaciones puesto que se condiciona a las mujeres a ser sumisas, dóciles y maternales.

También el currículo oculto del patriarcado se refleja en juguetes o recursos didácticos como textos escolares o bien en las actividades y juegos en las escuelas. Al respecto Caballero (2001) manifiesta:

Juegos y juguetes, libros de lectura, cuentos y películas infantiles, ilustraciones, carteles 
y mensajes, que muchas veces presentan una apariencia "asexuada" y neutral, nos pueden revelar los sutiles modos en que se filtran contenidos de género en el campo de la educación (s. n.)

No es extraño observar en varios textos escolares, las actividades 0 profesiones la exposición gráfica de niños vestidos de doctores, bomberos, albañiles, pastores, etc. Mientras que las actividades que pueden hacer las niñas se manifiestan como cocineras, limpiando la casa, cuidando a una muñeca; estos y varios aspectos se deben hacer la reflexión sobre los juegos, juguetes, recursos didácticos sexistas comenzando a elaborar textos que promuevan la equidad de género.

La siguiente Figura muestra los diferentes ejemplos cotidianos sobre la educación patriarcal y su currículo oculto.

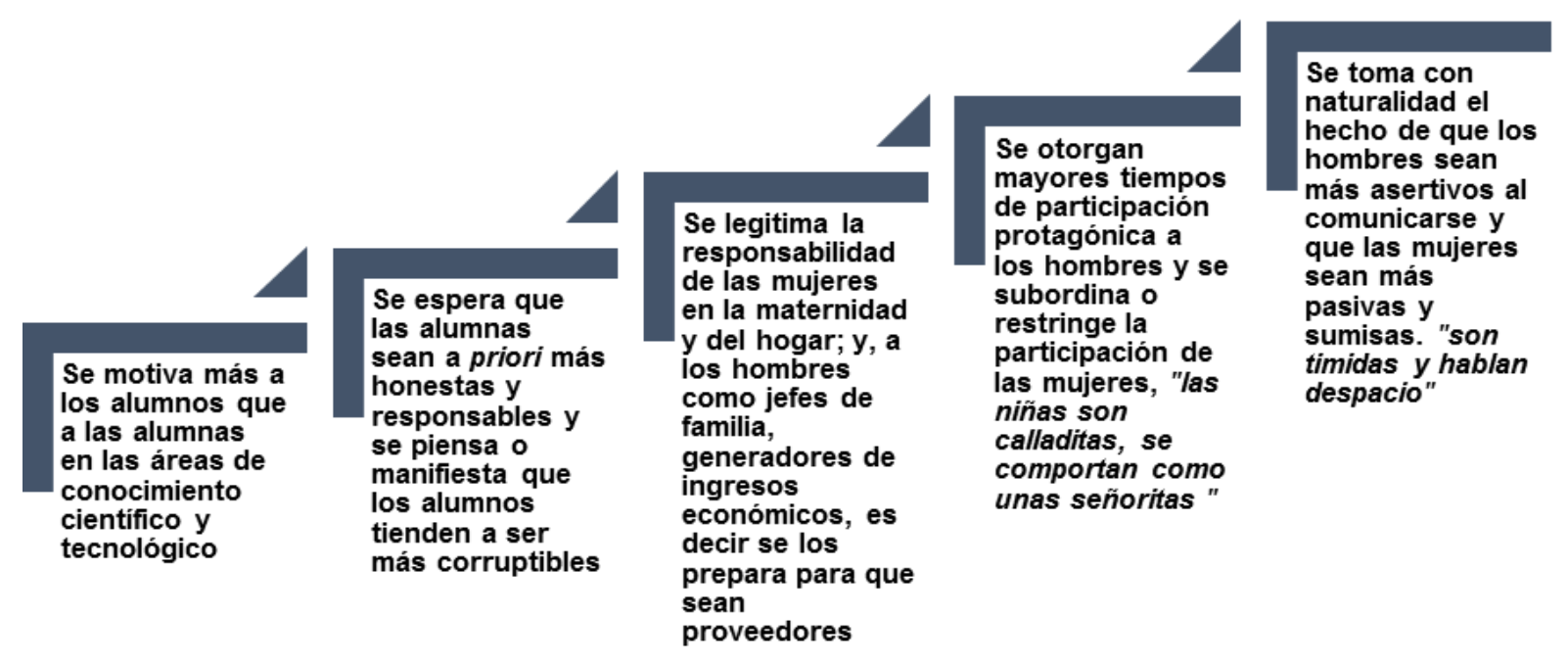

Figura 1. Ejemplos del currículo oculto del patriarcado. (Fuente: Elaboración propia. Extraído del libro en el libro Propuesta de currícula escolar para niños/as, adolescentes y jóvenes. Tomo IV jóvenes de secundaria. Centro de Información y Desarrollo de la Mujer (2010).

Los ejemplos de la Figura 1 van desde la familia, el sistema educativo, e incluso el contexto en el que se desarrollan los niños y niñas. Este sistema educativo patriarcal se muestra de forma ascendente, donde sin darse cuenta este va escalando y provocando que la violencia hacia la mujer comience desde simples actitudes o comportamientos hasta llegar a la violación de los derechos de la mujer. 
La educación alternativa y popular en la temática de género

La educación popular tiene como objetivo la formación de personas nuevas, donde estas sean protagonistas de su transformación social, para la construcción de una nueva sociedad más equitativa, donde se respeten los derechos y se reivindiquen los que son actualmente vulnerados; donde hombres y mujeres se concienticen y que la violencia hacia las mujeres no se naturalice.

El objetivo de la educación popular liberadora, es la formación de una persona nueva $\mathrm{y}$, de un pueblo nuevo como sujetos... que las personas nuevas se conviertan en protagonistas de la transformación social y de la nueva sociedad, es necesario que su opción por los oprimidos y las oprimidas explicite su dimensión política, combativa, comprometida para la construcción de una nueva sociedad. Es necesario que la gestación de la persona no se separe nunca de la gestación del pueblo nuevo, es decir libre y solidario. (Girardi, 2003, p. 139)

Entonces se concibe que en una sociedad nueva se respeten los derechos y se reconozcan los mismos. Así como que exista una disposición a trabajar la equidad de género, respetando los derechos de los demás que luchan por sus libertades, expresiones; por ser reconocidos y que se escuchen las diversas propuestas desde y para la realidad.

La educación popular tiene una gran tarea: trabajar el empoderamiento político - ético y pedagógico en la educación de personas jóvenes, adultos, familias y escuelas. En el aspecto de género se cuenta con el aporte de la Constitución Política del Estado, la ley Avelino Siñani - Elizardo Pérez y la ley integral para garantizar a las mujeres una vida libre de violencia a las mujeres acerca de la prevención y despatriarcalización de la educación en el país. Como lo planteado en el Foro de la Red de Educación Popular entre Mujeres de América Latina que ha trabajado estos temas hace dos décadas atrás:

E1 proceso educativo de personas jóvenes y adultas y la constitución de sujetos sociales debe estar permeado por género. Hay que darle un enfoque de transversalidad a los elementos constitutivos del concepto género y en especial centrarse en el análisis de las relaciones de poder entre hombres y mujeres, en la familia, la comunidad, incluyendo la política y las instituciones de la sociedad. (REPEM, 1996, p. 11)

Por esto se busca, desde la Declaración de los Derechos Humanos, la defensa de los mismos 
principalmente el de las mujeres; y se han construido propuestas desde América Latina, donde el medio por el cual podemos combatir la violencia de género es el camino de la educación, que todos y todas las personas sean formadas desde las familias, para así romper con los esquemas de poder patriarcal.

\section{La educación basada en la equidad de género}

La educación tiene mucho que ver acerca del tema de género y equidad de género, comienza desde la familia, desde la niñez la formación que se da en las escuelas primarias y secundarias hasta las instituciones de educación superior.

En los casos de feminicidio, las mujeres que fueron víctimas se habían formado en educación superior. Sin embargo, la información y formación acerca de la equidad de género en varios casos no se les ofrece.

Ante esta carencia, la Red de Educación Popular entre Mujeres (REPEM) ha construido varias propuestas sobre la forma de educación basada en la equidad de género no sólo en las escuelas sino en todos los espacios de la sociedad; donde se promueva la igualdad entre hombres y mujeres, como se menciona a continuación:
La educación como un medio para conseguir el desarrollo y la equidad debe contemplar en su proceso de enseñanza - aprendizaje, los elementos necesarios que permiten que hombres $y$ mujeres puedan integrarse y participar en la sociedad de manera más equitativa. (REPEM, 1996, p. 3)

Se ratifica que la educación es un medio importante en el cual se puede desarrollar una sociedad, respetando los derechos de hombres y mujeres por igual.

En la Figura 2 se muestran las principales propuestas para la equidad de género, construidos a lo largo de los años por la Red de Educación Popular entre Mujeres de América Latina. (REPEM) 


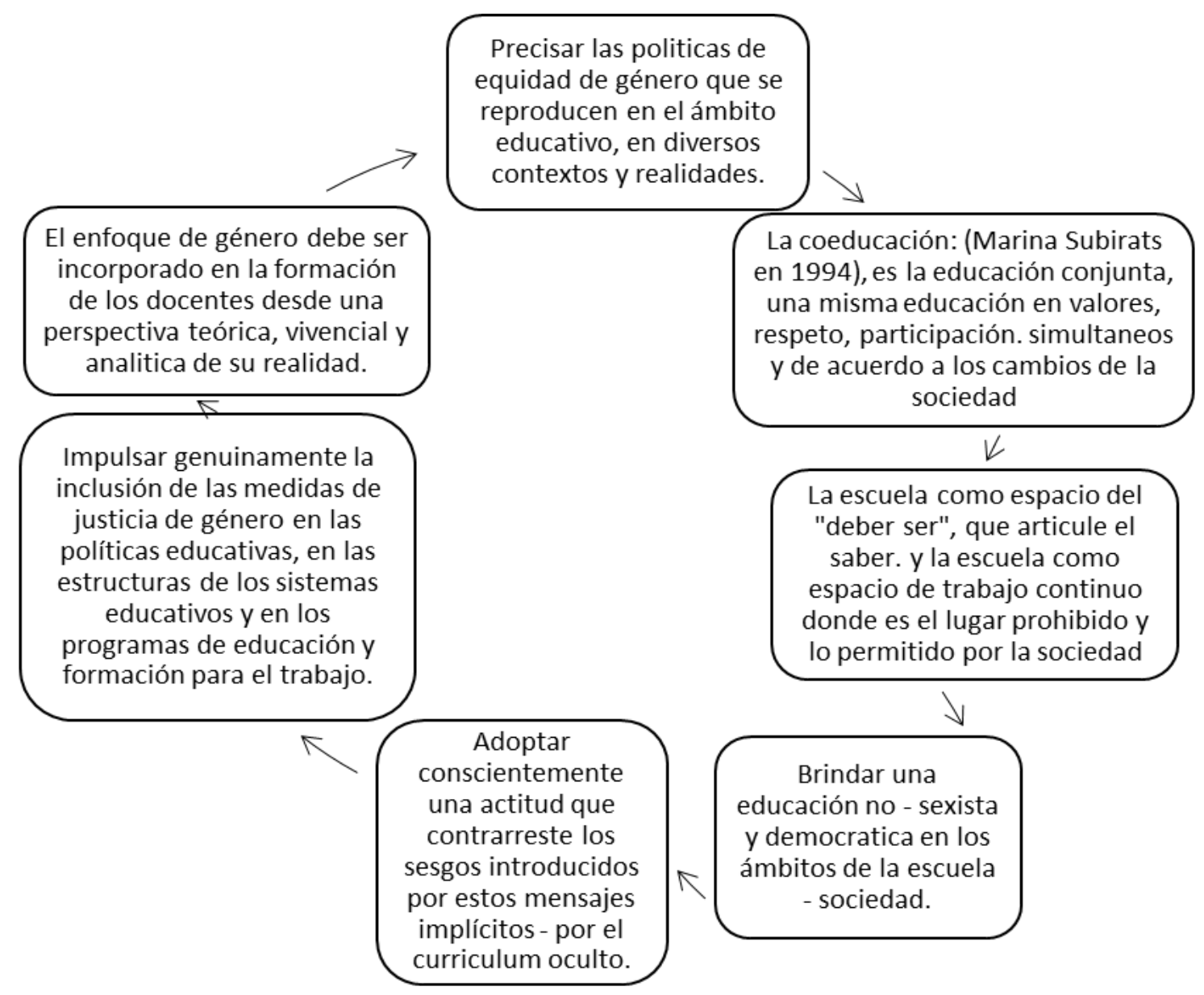

Figura 2. Propuestas para la educación en la equidad de género. (Fuente: Elaboración Propia. Extraído del Seminario Virtual de la Red de Educación Popular entre Mujeres de Educación de Adultos de América Latina, 2001 bajo el tema: "Educar para No Discriminar").

En todo este conjunto de propuestas se concibe a la educación como medio de contrarrestar los mensajes sexistas promoviéndose así nuevas políticas en las medidas de justicia de género, en un futuro de igualdad para todos y todas. Donde se respeten los derechos de hombres y mujeres, donde se formen personas en valores hacia el respeto al otro/a con igualdad de derechos y oportunidades.

\section{MÉTODO}

El estudio se circunscribió como una investigación de tipo descriptivo con características de Estudio de caso. El diseño de investigación fue No experimental- Transeccional.

La población fue todos los actores sociales que asistían y eran parte del Centro de Información y Desarrollo de 
la Mujer (CIDEM) de la ciudad de E1 Alto para beneficiarse de la atención social, legal y psicológica, esto en la gestión 2013.

Cabe resaltar que estos actores o participantes fueron los siguientes:

- Personal del CIDEM, entre los que se encuentran psicólogos y trabajadores sociales.

- Los familiares de una víctima de feminicidio íntimo como informantes dentro de la investigación Descriptiva con características de Estudio de Caso.

La muestra se hizo con la población responsable en el CIDEM, esto es, psicólogos y trabajadores sociales que fueron entrevistados. Otra muestra, respondiendo a la característica de Estudio de Caso, es la entrevista a una familiar de una víctima de feminicidio.

En el desarrollo del estudio se utilizó la técnica de la entrevista, y el instrumento fue la guía de entrevistas semiestructurada, que fue una herramienta clave para la recolección de datos dentro de la investigación.

\section{RESULTADOS}

Existe una dispersión significativa entre las respuestas de los especialistas y la teoría investigada. Sin embargo, se coincide en un $65 \%$ en 9 ítems del total de 15 que fueron las interrogantes presentadas a los especialistas, en tanto a aproximación teórica; lo que demuestra claramente que lo que se investigó en tanto a teoría fue y es un fundamento para la realización de una propuesta valedera para el diseño de un programa de prevención de violencia de género en parejas. Como se dijo, un $65 \%$ de las respuestas abordó una aproximación de $90 \%$ a la teoría y $10 \%$ de alejamiento ( 9 de 15 ítems), mientras que un $15 \%$ (3 del total de 15 ítems) respondió con un $80 \%$ de proximidad a la teoría y un $20 \%$ de alejamiento de la misma, quedando un $12 \%$ ( 2 de un total de 15 ) en cuanto a $70 \%$ de aproximación y $30 \%$ de alejamiento; por último, el $8 \%$ (1 de 15 ítems) sirvió para mostrar que los especialistas respondían coincidentemente en un $60 \%$ y $40 \%$ de alejamiento de la teoría.

No obstante, en las respuestas a la familiar de la mujer víctima de "feminicidio íntimo", las coincidencias con el fundamento teórico y las respuestas de los especialistas, todas las preguntas fueron respondidas, es decir, un $100 \%$, de manera coincidente a los fundamentos teóricos, en un $90 \%$ y solo $10 \%$ de alejamiento.

En tanto las coincidencias generales, se ha visto que:

- La violencia intrafamiliar y de género que devienen en posibles casos de "feminicidio íntimo", no se relacionan directamente con la formación académica, porque la 
dependencia emocional es un factor que bloquea todo tipo de antecedentes formativos.

- El ciclo violento está presente de manera muy influyente en los casos de "feminicidio íntimo", violencia intrafamiliar y durante el noviazgo; ya que ambos (víctima - agresor), están dentro de este ciclo pues es así en la que han aprendido a resolver los conflictos, donde la frecuencia y magnitud pueden ir en aumento culminando en feminicidio.

- La historia familiar de ambos también puede ser influyente para posibles casos de "feminicidio íntimo", puesto que la pareja busca un perfil de pareja cercanos a los que tenían sus padres o madres y si en su familia han vivido o presenciado actos violentos para resolver los conflictos es un aprendizaje subjetivo.

- La dependencia emocional existente en parejas que están dentro del ciclo violento es muy influyente, ya que existe una co-dependencia entre el agresor y víctima, ambos muestran baja autoestima, justifican la violencia cada uno desde su punto de vista, no queriendo romper con la relación violenta o no aceptando que viven en violencia.

- La incapacidad de comunicación en pareja es un factor para que se den casos de violencia intrafamiliar esto tiene que ver mucho en como el agresor ha aprendido a manifestar su insatisfacción.
- El factor social donde subjetivamente se da roles, comportamientos, actitudes desde la familia hasta la sociedad que se debe cumplir en ambos géneros.

- El factor económico es influyente por los roles asignados a lo largo de la historia donde el varón es concebido como proveedor y la mujer concebida para desarrollarse en el ámbito doméstico, a pesar de que las necesidades son otras actualmente en varios casos se cree que la mujer debe de estar ocupada en el hogar y es ahí donde se detona los conflictos.

- El factor cultural también es influyente puesto que, aún se sigue teniendo ese modelo de comportamiento entre el hombre y la mujer, donde la víctima de violencia cree que no puede separarse porque será mal vista ante la sociedad, que no puede dejar sin padre a sus hijos y que no será respetada en su entorno.

El factor educativo interviene desde que mujeres $u$ hombres nacen, donde el ser humano aprende desde su entorno y si su entorno ha sido violento, se da prioridades o se relega entre géneros en el ámbito escolar, social, y laboral como un "curriculum oculto" del sistema patriarcal que se sigue subjetivamente.

A continuación se presentan algunos ejemplos del Programa Educativo Prevención de Violencia y "Feminicidio Íntimo" a parejas de la ciudad de E1 Alto: 


\section{Formemos juntas y juntos familias sin violencia}

Eje temático: Las tareas de cada uno/a de la pareja y la corresponsabilidad dentro de la familia.

\begin{tabular}{|c|c|c|c|c|}
\hline Competencia & Indicadores & Contenido & Actividades & Recursos \\
\hline $\begin{array}{l}\text { Genera en el grupo un } \\
\text { ambiente ameno y } \\
\text { participativo entre los } \\
\text { participantes. } \\
\text { Crea un ambiente de } \\
\text { respeto mutuo y de } \\
\text { confidencialidad para } \\
\text { hablar sobre la violencia de } \\
\text { género y en la familia. } \\
\text { Valora la } \\
\text { corresponsabilidad que } \\
\text { debe prevalecer dentro de } \\
\text { la familia. }\end{array}$ & $\begin{array}{l}\text { Conoce la importancia de la } \\
\text { corresponsabilidad dentro } \\
\text { de la familia. } \\
\text { Reflexión conjunta sobre las } \\
\text { tareas que cada uno/a } \\
\text { realiza en su cotidianidad. } \\
\text { Práctica de la } \\
\text { corresponsabilidad dentro } \\
\text { de la familia para evitar } \\
\text { conflictos de las tareas del } \\
\text { hogar. } \\
\text { La pareja varón valora el } \\
\text { trabajo doméstico de la } \\
\text { mujer dentro del hogar. } \\
\text { Proponer ideas en apoyo } \\
\text { hacia su pareja en las tareas } \\
\text { del hogar. }\end{array}$ & $\begin{array}{l}\text { Conceptual: } \\
\text { Conociendo a los y las } \\
\text { participantes del curso. } \\
\text { Procedimental: } \\
\text { Establecer reglas conjuntas } \\
\text { y construidas en grupo } \\
\text { para el desarrollo de las } \\
\text { sesiones posteriores. } \\
\text { Reconocer el doble rol de } \\
\text { trabajo de la mujer } \\
\text { "El reloj" } \\
\text { Actitudinal: } \\
\text { Promover la } \\
\text { corresponsabilidad dentro } \\
\text { de la familia. }\end{array}$ & $\begin{array}{l}\text { Presentación del curso a los y las participantes. } \\
\text { Motivación a los y las participantes con la técnica } \\
\text { "Juntando las mitades". } \\
\text { Propuestas de las reglas dentro del curso por parte de } \\
\text { los y las participantes donde debe prevalecer el } \\
\text { compromiso, confidencialidad y respeto de } \\
\text { opiniones. } \\
\text { Construcción de las tareas de las mujeres dentro o } \\
\text { fuera del hogar mediante la elaboración de un reloj, } \\
\text { así mismo las tareas de los hombres con la misma } \\
\text { técnica. } \\
\text { Se promueve la reflexión conjunta sobre las tareas } \\
\text { que cada uno o una de la pareja realiza dentro de la } \\
\text { familia. } \\
\text { Se muestra un video de corresponsabilidad dentro } \\
\text { del hogar. } \\
\text { Se reflexiona en conjunto sobre la importancia de la } \\
\text { corresponsabilidad dentro de la familia así mismo } \\
\text { reconociendo que muchas mujeres realizan tareas y } \\
\text { responsabilidades de ser madre de familia y sustento } \\
\text { del hogar al igual que su pareja. } \\
\text { Se construye en conjunto algunas ideas para } \\
\text { promover la corresponsabilidad dentro de la familia. }\end{array}$ & $\begin{aligned} \checkmark & \text { Imágenes de periódico } \\
& \text { recortadas por la mitad, que } \\
& \text { sean bajo un contenido en la } \\
\text { que muestre a la familia, } & \text { pareja, mujeres trabajando. } \\
\checkmark & \text { Cinta masquin. } \\
\checkmark & \text { Tarjetas de cartulina de } \\
& \text { colores de 18cm por } 12 \mathrm{~cm} \\
\checkmark & \text { Marcadores gruesos de } \\
& \text { colores } \\
\checkmark & \text { Ganchos pequeños } \\
\checkmark & \text { Hojas sabana cantidad } \\
\checkmark & \text { aproximada } 8 \text {. } \\
\checkmark & \text { Tarjetas de colores }\end{aligned}$ \\
\hline
\end{tabular}


Eje temático: Las tareas de cada uno/a de la pareja y la corresponsabilidad dentro de la familia.

Población dirigida: Padres y madres de familia

\section{Poniendo en práctica mi actividad:}

1. La facilitadora y/o facilitador debe estar antes para preparar los materiales y adecuar el aula para el desarrollo de la sesión.

2. Los y las participantes deben estar sentados en círculo para esta actividad esto con el objetivo de motivar la participación.

3. La facilitadora y/o facilitador entrega las imágenes de periódico mezcladas, ellos y ellas deben buscar la mitad faltante entre sus compañeros/as, después de encontrar la imagen faltante con su compañero o compañera se les pide unirla con la cinta masquin. Posteriormente se les pide a los/las participantes después de unir la imagen, se presente primero los del lado izquierdo, y después del lado derecho. En la que deben incluir en la conversación el nombre, signo zodiacal, plato favorito, hobbies o gustos y por qué le intereso participar en este curso. Ejemplo: Mi nombre es Carla, soy de cáncer, me gusta el plato paceño, me gusta el fútbol, me intereso participar al curso por... a la conclusión de la conversación el/la compañero/a de lado derecho presentará en voz alta a su compañero/a. Por último, a medida que las y los participantes se vayan presentando el/la facilitador/a deberá anotarla en las tarjetas y entregársela. Al finalizar la actividad se les explica que esta es una forma de conocerse de forma más amigable y lúdica porque no sólo se conoce el nombre sino los gustos y la expectativa de participar al curso.

4. La facilitadora y/o facilitador motivara a los y las participantes la importancia de las reglas para las sesiones, esto para que puedan expresar sus opiniones en las diferentes temáticas de forma participativa y conjunta, en un ambiente de respeto y libertad de opiniones y recordarles que estas sesiones son importantes si son tomadas en pareja. Pedir a los y las participantes que sugieran reglas dentro de los talleres, o expresen como quieren sentirse después de cada sesión, las reglas se escribirán en la hoja sabana donde la facilitadora y/o facilitador puede sugerir también otras reglas. Estas deben estar aprobadas por la mayoría de los y las participantes.

5. Se agrupan dos grupos de sólo varones y otros dos de sólo mujeres de igual cantidad, para esto se hace una actividad lúdica donde se les pide a los y las participantes que se muevan por todo el espacio con ayuda a la música; donde la facilitadora o el facilitador ordena que se agrupen parejas que se junten con un abrazo, después se les pide que vuelva a desunirse y que se muevan otra vez por el espacio y formar grupos de tres que se una espalda con espalda o grupos de cuatro que se junten frente con frente y así sucesivamente formando grupos de igual cantidad en las que deben de estar de dos a tres grupos de sólo varones de igual cantidad y los mismo con las mujeres. 
Eje temático: Las tareas de cada uno/a de la pareja y la corresponsabilidad dentro de la familia.

Población dirigida: Padres y madres de familia

\section{Poniendo en práctica mi actividad:}

6. A la conformación de los grupos la facilitadora y/o facilitador entrega a cada grupo la hoja sabana en la que deben estar dibujadas dos relojes que indiquen las doce horas de la mañana y las doce horas de la tarde y noche. Se reparte estas dos o tres hojas sabana a los grupos de varones donde ellos deben anotar las actividades y/o tareas que hacen durante toda la jornada; las otras dos o tres sabanas se les reparte también a los grupos de mujeres restantes en la que deben hacer lo mismo. Se sugiere también que los grupos de las mujeres hagan el trabajo en otro ambiente para que exista más confianza y confidencialidad entre ellas.

7. Se pide al grupo de varones que expongan su reloj una vez acabado, se les hace las siguientes preguntas: ¿Será que nuestra pareja tiene el doble trabajo dentro y fuera de la familia?, ¿Cuándo ven a su pareja realizando las tareas del hogar las ayudan?, ¿Enseñan a sus hijos o hijas sobre las tareas del hogar?, ¿Ustedes creen que las responsabilidades compartidas en la familia son buenas para la mejor convivencia?

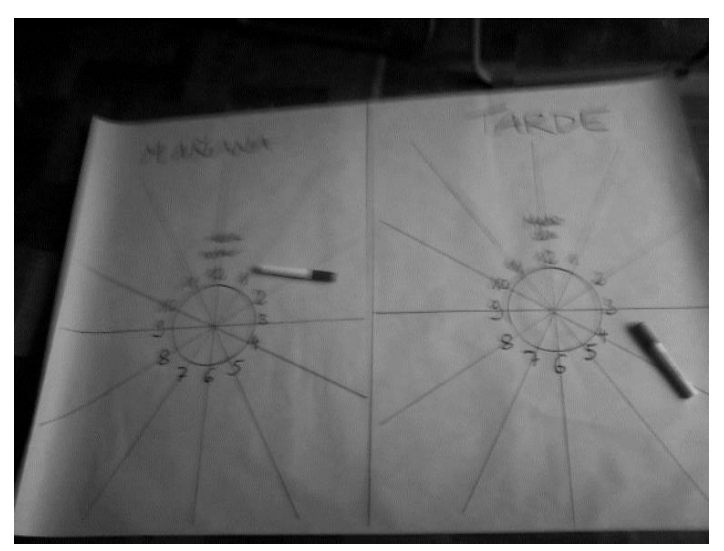

8. Se les pide a las mujeres que hagan el mismo ejercicio, lo mismo harán las mujeres en las que se hace una comparación de las tareas que realiza cada uno/a dentro del hogar y fuera de este; a las mujeres se les pregunta lo siguiente: ¿A qué hora te despiertas para hacer las tareas?, ¿Creen ustedes que tienen doble tarea al ser mujeres y también ser madres?, ¿Sus parejas les apoyan cuando saben que están trabajando?, ¿Sus hijos les apoyan en las tareas de casa?

9. Posteriormente se les pide a todos y todas las participantes que reflexionen sobre las tareas que cada uno/a realiza observando los relojes que cada grupo ha realizado comparando las mismas y haciendo la diferencia.

10. Consecutivamente la facilitadora y/o facilitador muestra el video "Un sueño imposible", donde al finalizar el mismo se les pide a los y las participantes a que respondan las siguientes preguntas: ¿Qué actividades realiza la mujer en el video?, ¿Qué actividades realiza el hombre?, ¿la mujer y la niña descansan en algún momento?, ¿Realiza alguna tarea el niño en la casa... y el padre realiza alguna tarea también?, ¿El video muestra que ambos trabajan pero es el mismo salario que reciben ambos por su trabajo?, ¿Qué sueña la pareja al anochecer?, ¿Será que hombres y mujeres podemos realizar las mismas tareas? 
Eje temático: Las tareas de cada uno/a de la pareja y la corresponsabilidad dentro de la familia.

Población dirigida: Padres y madres de familia

\section{Poniendo en práctica mi actividad:}

11. La facilitadora y/o facilitador deberá promover la participación con estas preguntas y también que la participación sea respetuosa y con un tiempo determinado para cada participación.

12. Seguidamente la facilitadora y/o facilitador les reparte fichas a todos/as las participantes en la que en grupos de tres deberán escribir en cada ficha tareas que se puede hacer mutuamente, explicando que en la familia debe crearse un ambiente de apoyo mutuo y respeto. Esto para que los hijos e hijas aprendan desde muy pequeños la importancia de las responsabilidades del hogar.

13. Por último la facilitadora y/o facilitador colocara al centro del espacio el termómetro, en la que se les pide a los y las participantes voluntariamente a que coloquen un grado haciéndoles las siguientes preguntas: ¿Qué grado le colocan a la sesión y por qué?, ¿La actividad del reloj qué grado le colocarían y por qué?, ¿El video que se les mostró qué grado le colocarían y por qué?, ¿Las propuestas de todos nosotros para compartir las responsabilidades dentro y fuera de hogar qué grado le pondría y por qué?

\section{IMPORTANTE}

Se sugiere que padres y madres en conjunto estén constantemente a los cursos puesto que el programa está dirigido a las parejas, para sensibilizarlas en las temáticas así también ellos en conjunto propongan desde sus experiencias estrategias de la no violencia en la familia y hacia las mujeres. 


\section{CONCLUSIONES}

Se responde al objetivo general de la investigación, estableciendo el criterio que toda relación de pareja que presente problemas que lleven al "ciclo de violencia" e incluso al "feminicidio íntimo", tiene su origen en el aspecto afectivo, el aspecto social y el aspecto cultural; estos tres elementos son los que, en correspondencia con la relación de pareja, pueden tratarse en la medida como para prevenir problemas mayores. Tres causas que son intervenidas con aspectos metodológicos y estrategias de trabajo, presentes en el programa propuesto en la presente investigación, programa que lleva el nombre de "Formemos juntos y juntas una familia sin violencia".

Así mismo el factor educativo es uno de los más importantes pues refleja la violencia hacia las mujeres y la extrema violencia que es el "feminicidio íntimo" como un problema estructural que ha sido aprendida desde la familia, medios televisivos, medios sociales, instituciones educativas.

En definitiva, con esta investigación no se ambicionó llegar al "ginocentrismo", en la que se eleve a la mujer como centro de todo, y que se justifique el uso de la violencia de la mujer hacia el hombre; lo que se quiso fue lograr fomentar, a través del factor educativo, los derechos humanos, respeto a la igualdad de género donde haya las mismas oportunidades y exista una justicia equitativa en casos de violencia.

\section{REFERENCIAS}

Centro de Información y Desarrollo de la Mujer (CIDEM). (2010). Propuesta de currícula escolar para niños/as, adolescentes y jóvenes. La Paz: Editorial Jivas

Centro de Información y Desarrollo de la Mujer (CIDEM). (2010). Diagnóstico con hombres. La Paz : Imprenta Jivas

Constitución Política del Estado Plurinacional de Bolivia. (2008). Nueva Constitución Política del Estado. La Paz: Editorial Honorable Cámara de Diputados

Frabonni, F. (2002). El libro de la pedagogía y la didáctica. Madrid: Editorial Casa del libro

Girardi, G. (2003). Formando Actores en La Alternativa a la Globalización Neoliberal. Los nuevos desafíos de la educación popular. La Paz: Editorial: OFAVIN

Grupo Cultural. (2010). Diccionario de Pedagogía y Psicología. Madrid: Editorial Cultural S.A

Lagarde, M. (2006). Feminicidio una Perspectiva Global. México: Editorial Centro de Investigaciones Interdisciplinarias en Ciencias y Humanidades.

Ley $\mathrm{N}^{\mathrm{o}}$ 070. (2011). Ley de la Educación "Avelino Siñani y Elizardo Pérez". La Paz: Editorial U.P.S

Patzi, F. (2007). Etnofagia Estatal. Modernas formas de Violencia Simbólica (Análisis de la Reforma Educativa en Bolivia). La Paz: Editorial DRIVA 
Red de Educación Popular Entre Mujeres Afiliada al Consejo de Educación de Adultos de América Latina (1996). Santiago, Chile: Editorial REDEM

Valenzuela, M. (2001). Educar para no Discriminar, Sistema Educativo.
Montevideo, Uruguay: Editorial Red de Educación Popular Entre Mujeres Afiliada al Consejo de Educación de Adultos de América Latina 